\title{
Tetrasomic inheritance of isoenzyme markers in the highbush blueberry, Vaccinium corymbosum L.
}

\author{
S. L. Krebs and \\ J. F. Hancock
}

Department of Horticulture, Michigan State

University, East Lansing, Michigan 48824, U.S.A.

Segragation ratios at four enzyme loci (Mdh-2, Pgi-2, 6Pgd-2, and Got-3) in Vaccinium corymbosum (4x) cultivars were in close agreement with the expectations of tetrasomic inheritance. Random chromosome segregation was suggested by the absence of double reduction progeny genotypes and previous reports of bivalent pairing in this species. A common species origin of autotetraploid highbush blueberry and other Vaccinium polyploids is proposed. Different genetic and evolutionary consequences of polysomic inheritance versus disomic inheritance are discussed with reference to the literature on polyploids.

\section{INTRODUCTION}

The subgenus of "true" blueberries, Vaccinium section Cyanococcus $(\mathrm{x}=12)$, is composed of diverse and widely distributed species which form a polyploid complex of diploids, tetraploids, and hexaploids. There is currently no consensus regarding the origins of these polyploids, whether they derived from intra- or interspecific hybridization among the diploid species, and subsequently whether they are autopolyploids, allopolyploids, or segmental allopolyploids. The nature of genome amplification in the cultivated highbush blueberry, $V$. corymbosum $(4 \mathrm{x})$, is of particular interest, since knowledge of chromosome pairing behaviour and mode of inheritance at the tetraploid level will affect breeding strategies in addition to providing information about phylogenetic relationships within this subgenus.

Polyploidy in blueberry species has been discussed mainly on the basis of morphology, ecology, and cytology. In the monograph on eastern North American Cyanococcus species by Camp (1945), $V$. corymbosum was designated an allotetraploid hybrid complex. An allopolyploid origin for $V$. corymbosum and four related tetraploid taxa was suggested by the finding that the tetraploids as a group exhibited higher pollen stainability than a

* Michigan Agricultural Experiment Station Journal Article No. 12992. group of seven diploid species (Cockerham and Galletta, 1976). Several cytogenetic studies of meiotic pairing and disjunction in highbush cultivars revealed a preponderarice of bivalent forma.tion, which was interpreted as evidence for nonrandom, preferential pairing of chromosomes (Newcomer, 1941; Stushnoff and Hough, 1968; Jelenkovic and Hough, 1970). However, in these same studies and others which have examined tetraploid cultivars and related species (Jelenkovic and Harrington, 1971), multivalents and secondary associations of bivalents at metaphase I were occasionally observed, indicating that $V$. corymbosum may be an autopolyploid. Regular chromosome pairing in polyploids is not conclusive evidence for allopolyploidy, since many autopolyploids undergo extensive diploidization of their genomes such that multivalent formation among homologues is restricted.

Inheritance data are the least equivocal means of distinguishing between auto- and allotetraploidy. Because of preferential pairing in allotetraploids, they exhibit independent assortment at the duplicated loci (disomic inheritance) and fixed heterozygosity where these loci are homozygous for different alleles. Segregation in autotetraploids is tetrasomic - for diagnostic heterozygous genotypes, random association of the four homologues during the first meiotic division results in a lower frequency of homozygous gametes than would be produced by an allotetraploid of the same 
genotype. Draper and Scott (1971) observed segregation ratios for the recessive "albino seedling" trait in $V$. corymbosum and obtained results largely consistent with tetrasomy. However, they found a significant excess of heterozygotes which was attributed to some degree of preferential pairing among chromosomes bearing the marker gene, or possibly to segregation distortion caused by the lethality of the mutant albino allele.

Inheritance studies of morphological characters in Vaccinium have historically been limited by the scarcity of single gene polymorphisms (Galletta, 1975; Lyrene, 1988). Our objective was to tap an alternate source of marker genes, isoenzyme polymorphisms, for observing segregation patterns in the tetraploid highbush blueberry, $V$. corymbusum. There are many precedents for this kind of analysis in plants. Electrophoretic evidence of tetrasomic inheritance has been obtained for Medicago sativa (Quiros, 1982), Solanum tuberosum (Martinez-Zapater and Oliver, 1984; Quiros and McHale, 1985), Haplopappus spinulosus (Hauber, 1986), Tolmiea menziesii (Soltis and Soltis, 1988), Heuchera micrantha (Soltis and Soltis, 1989), and Heuchera grossulariifolia (Wolf et al., submitted). Among allopolyploids, disomic inheritance has been documented for duplicated enzyme loci in tetraploid Tragopogon mirus and T. miscellus (Roose and Gottlieb, 1976), triplicated loci in hexaploid Triticum aestivum (Hart, 1983), and quadruplicated loci in octaploid Fragaria $\times$ ananassa (Arulsekar et al., 1981).

\section{MATERIALS AND METHODS}

Progeny were derived from crosses among four tetraploid highbush cultivars, V. corymbosum, which differed genotypically at several electrophoretic loci. These cultivars were "Rubel", a wild plant selection, and "Jersey", "Bluejay", and "Spartan", genotypes which have resulted from one to five cycles of pedigree selection beyond the initial wild accessions. Seeds were germinated and seedlings grown in a growth chamber (14 hour daylength, $15-25^{\circ} \mathrm{C}$ diurnal temperature). Beginning with the 5-6 leaf stage of seedling growth, tissue was prepared for starch gel electrophoresis.

The extraction buffer was made as follows: $0 \cdot 1 \mathrm{M} \mathrm{K}$-phosphate buffer $(p \mathrm{H} \mathrm{7} \cdot 5), 5 \mathrm{mM}$ EDTA, $10 \mathrm{mM}$ dithiothreitol, $0 \cdot 1$ per cent 2 -mercaptoethanol, and 0.5 per cent Tween-80. To make a

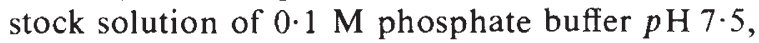
$84 \mathrm{ml}$ of $0.2 \mathrm{M} \mathrm{K}_{2} \mathrm{HPO}_{4}$ (dibasic) was added to $16 \mathrm{ml}$ of $0.2 \mathrm{M} \mathrm{KH}_{2} \mathrm{PO}_{4}$ (monobasic) and diluted with $\mathrm{H}_{2} \mathrm{O}$ to a final volume of $200 \mathrm{ml}$. After dissolving the rest of the components, the extraction buffer was adjusted to $p \mathrm{H} 8.0$ with $4 \mathrm{~N} \mathrm{KOH}$.

Prior to leaf protein extraction, insoluble PVPP (Sigma \#P-6755) was hydrated overnight in the above extraction buffer. Seedling leaves were ground in spot plate wells containing extraction buffer (approximately 5:1, v/w, buffer:tissue ratio) plus a small amount (weighing spatula tip) of the hydrated PVPP. The crude extract resembled a wet slurry rather than a thick paste. The leaf extract was soaked onto filter paper wicks through a $35 \mu \mathrm{m}$ nylon screen. Throughout the process, all materials were maintained at $4^{\circ} \mathrm{C}$.

Seven enzyme systems have been consistently resolved from blueberry leaf extractions; four of these were used in the present study. The gel and electrode buffer systems, as well as the enzyme staining protocols, were adopted from previous reports without major modifications. The staining schedules which gave best results were those of Conkle et al. (1982) for glutamate oxaloacetate transaminase (GOT) and 6-phosphogluconate dehydrogenase (6PGD), Soltis et al. (1983) for isocitrate dehydrogenase (IDH), shikimate dehydrogenase (SKDH), and phosphoglucomutase (PGM), and Vallejos (1984) for phosphoglucose isomerase (PGI) and malate dehydrogenase $(\mathrm{MDH})$. Standard gel and electrode buffers used were the morpholine-citrate system, $p \mathrm{H} \mathrm{6 \cdot 1} \mathrm{(Clay-}$ ton and Tretiak, 1972) for resolving $\mathrm{MDH}, \mathrm{IDH}$, 6PGD, and SKDH, and the lithium borate, triscitrate system, $p \mathrm{H} 8.3$ (Scandalios, 1969) for resolving GOT, PGI, and PGM.

For each segregating locus, a chi-square test of fit of progeny ratios to the following genetic models was performed: monogenic inheritance (diploidy), digenic-disomic inheritance (allotetraploidy), and digenic-tetrasomic inheritance (autotetraploidy). Segregants were classed by electrophoretic phenotype, heterozygous or homozygous, rather than by genotype. This approach is more reliable since it does not require assigning gene dosages based on a visual assessment of differential band staining intensity among heterozygotes.

\section{RESULTS}

Segregation was observed at six loci encoded by four dimeric enzymes: $M d h-1, M d h-2$, Got-3, Pgi2, 6Pgd-1, and $6 P g d-2$ (figs. 1-3, table 1). In all segregating crosses, one or both parents were tribanded, diallelic heterozygotes carrying one to three copies of each allele per locus. The effect of 
Table 1 Chi-square tests for mode of inheritance at four electrophoretic loci

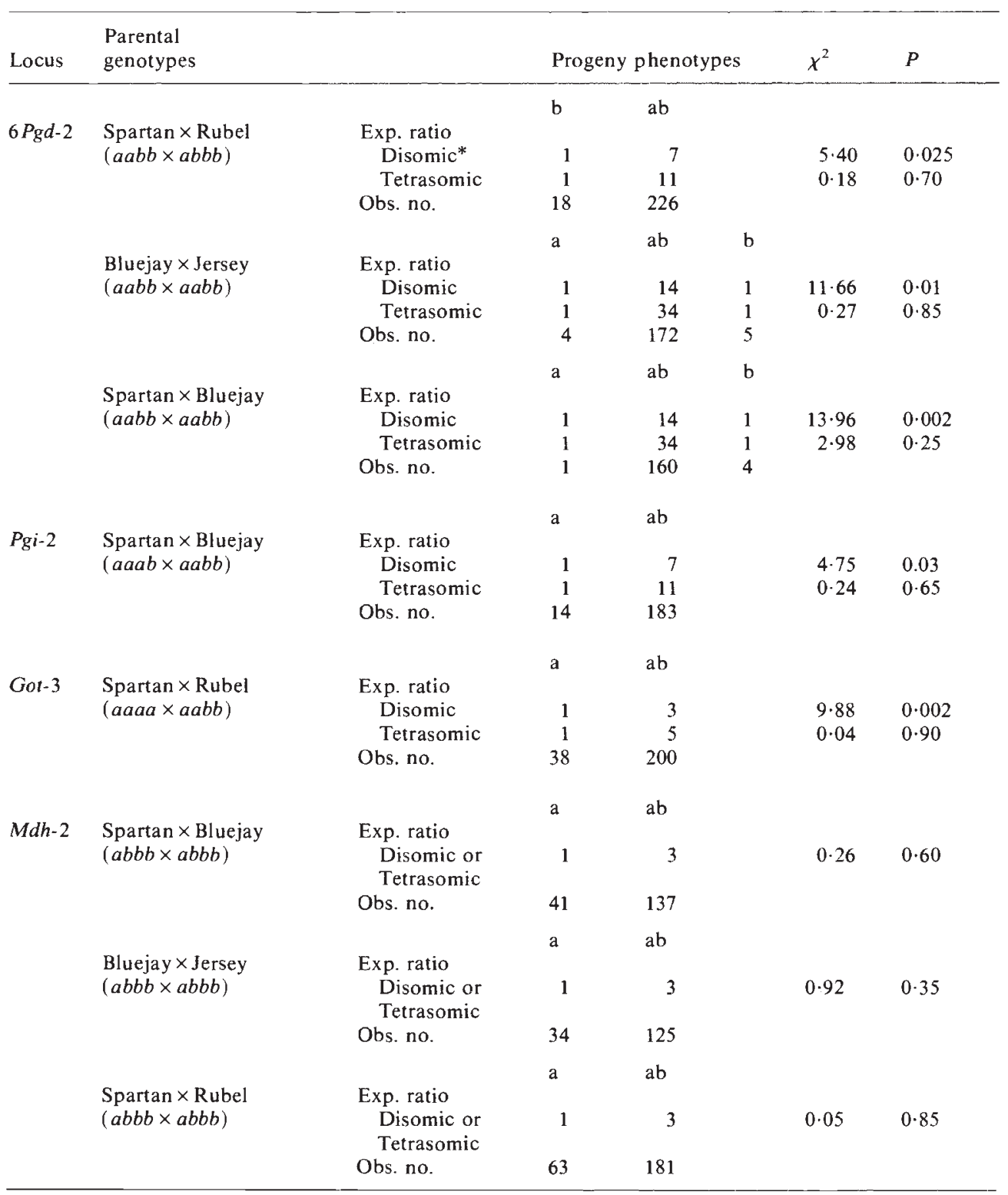

* Alleles were assumed to be in a configuration that would not result in fixed heterozygosity.

gene dosage on electrophoretic phenotype appeared to be a multiplicity of heterozygote banding patterns. Diallelic parents and progeny exhibited either a "balanced" tri-banded phenotype in which the two homodimers were equal in staining intensity and both less intensely stained than the heterodimer mid-band, or one of two "unbalanced" phenotypes in which one homodimer and the heterodimer had greater staining intensity than the remaining homodimer (figs.
1-3, A-E). None of the parent cultivars showed complex banding patterns (six or more bands per locus) indicative of tri- or tetra-allelic genotypes for dimeric proteins.

Chi-square tests for mode of inheritance in tetraploid $V$. corymbosum are given for four diagnostic loci in table 1 . At the $6 P g d-2, P g i-2$, and Got-3 loci, observed progeny phenotypic ratios were consistently best explained by the assumption of tetrasomic inheritance, with $P$ values ranging 
from 0.25 to $0 \cdot 90$. For these three loci, the alternative genetic hypothesis, digenic-disomic inheritance, was statistically rejected $(P<0.05)$ in all crosses. Segregation ratios at a fourth locus, $M d h$ 2 , provided evidence for gene duplication (i.e., digenic control) without distinguising between disomy and tetrasomy. The $3: 1$ phenotypic distribution among progeny at this locus most likely results from a cross between diallelic parents which are both carrying the same allele, $M d h-2^{\mathrm{b}}$, in triplicate (fig. 1). Monogenic control of $M d h-2$ segregation in these crosses would result in a $1: 2: 1$ expected phenotypic ratio that is clearly at odds with the observed distribution.

Progeny distributions of $1: 1$ were observed for several loci and parental combinations: $6 P g d-1$ in

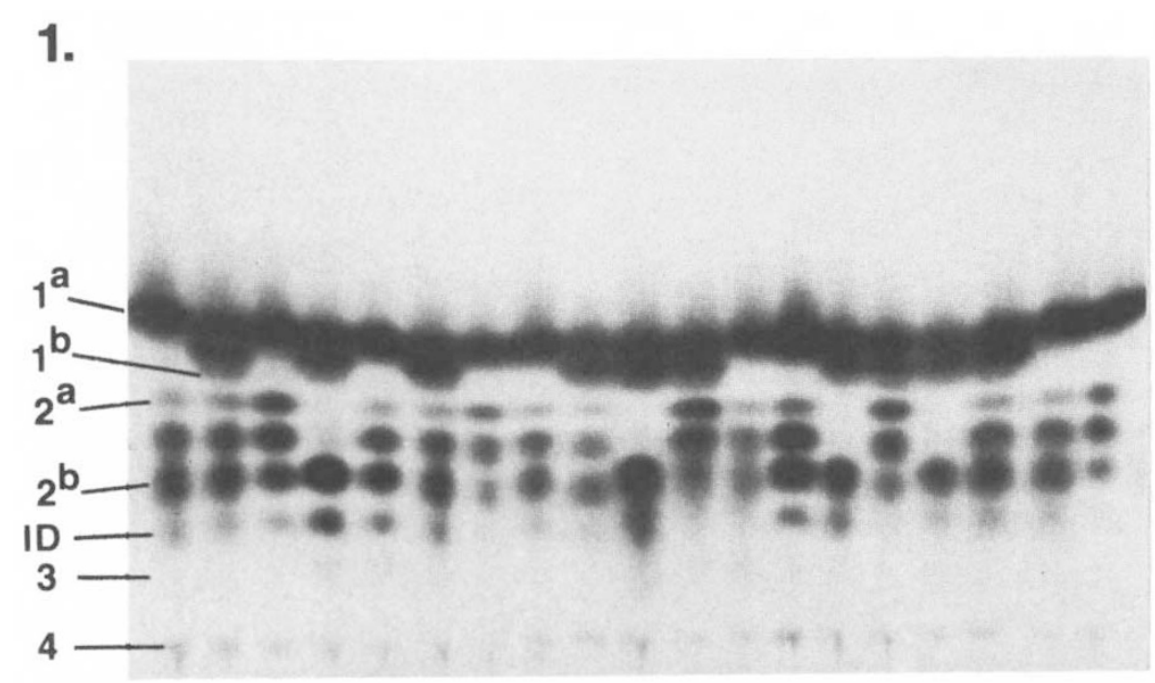

A B C D E

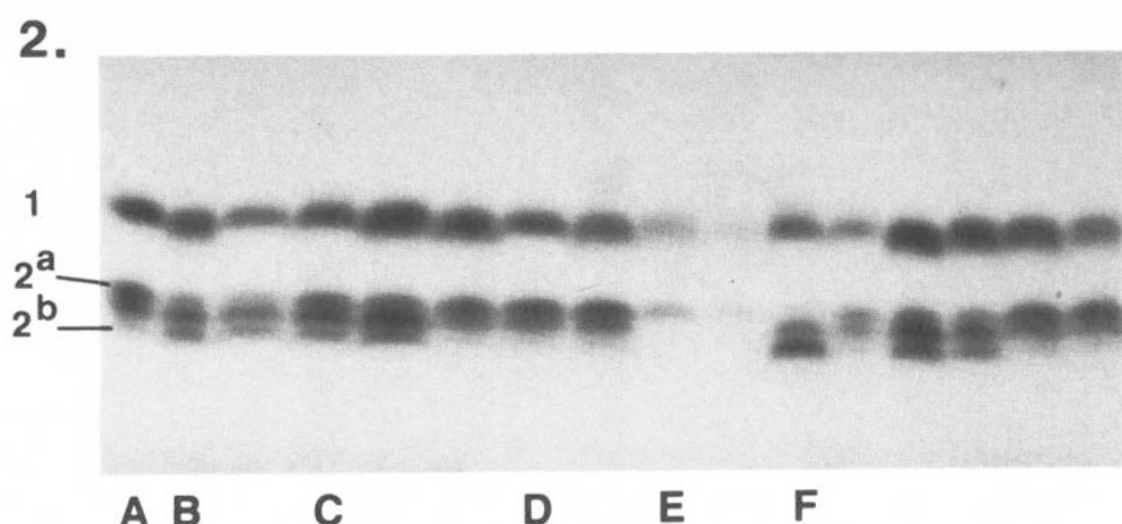

Figures 1-3 Tetraploid segregation patterns at loci encoded by three dimeric enzymes; anodal direction is above. Numbers and letter superscripts at lefthand margins of photographs indicate putative loci and alleles. Bottom letters are parents (A and B) and representative progeny which have been assigned genotypes for illustrative purposes. Figure 1. Segregation in the cross "Bluejay" $\times$ "Jersey" at the $M d h-1$ locus (parental genotypes $a a a a \times a a a b$ ) and the $M d h-2$ locus (parental genotypes $a b b b \times a b b b$ ). For $M d h-1$, the expected progeny genotypic ratio is 1 aaaa $(\mathrm{C}, \mathrm{E}): 1$ aaab(D) or a phenotypic ratio of $1 a: 1 a b$. The expected genotypic ratio for $M d h-2$ is $1 a a b b(\mathrm{C}): 2 a b b b(\mathrm{E}): 1 b b b b(\mathrm{D})$ or a phenotypic ratio of $3 a b: 1 a$ (digenic-disomic or digenictetrasomic). ID designates a putative interlocus heterodimer formed between $M d h-2^{b}$ and $M d h-3$. Figure 2. Progeny segregation at the Pgi-2 locus in the cross "Spartan" $\times$ "Bluejay", parental genotypes aaab $\times a a b b$. The expected genotypic distribution among offspring is $1 a a a a(\mathrm{E}): 5 a a a b(\mathrm{D}): 5 a a b b(\mathrm{C}): 1 a b b b(\mathrm{~F})$, or a phenotypic ratio of $11 a b: 1 a$ (digenic-tetrasomic). Figure 3. Progeny segregation in the cross "Spartan" $\times$ "Rubel" at the 6 Pgd-1 locus (parental genotypes aaaa $\times a a a b)$ and the $6 P g d-2$ locus (parental genotypes $a a b b \times a b b b)$ ). For $6 \mathrm{Pgd}-1$, the expected progeny genotypic ratio is $1 a a a a(\mathrm{C}, \mathrm{E}): 1 a a a b(\mathrm{D}, \mathrm{F})$. For $6 \mathrm{Pgd}-2$, the expected tetrasomic segregation pattern is $1 b b b b(\mathrm{D}): 5 a b b b(\mathrm{~F}): 5 a a b b(\mathrm{C}): 1 a a a b(\mathrm{E})$ or a phenotypic ratio of $11 a b: 1 b$. 


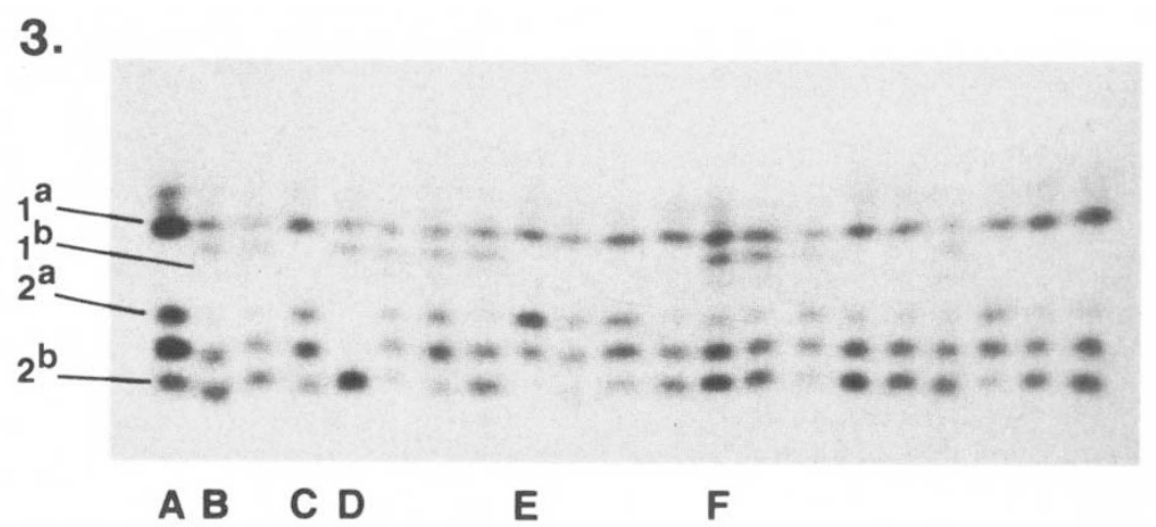

the crosses "Spartan" $\times$ "Rubel" (fig. 3) and "Bluejay" $\times$ "Jersey", Got-3 in the cross "Spartan" $\times$ "Bluejay", Pgi-2 in the cross "Spartan" $\times$ "Rubel", and $M d h-1$ in the cross "Bluejay" $\times$ "Jersey" (fig. 1). Inheritance data from these crosses is not reported in table 1 because the parental genotypes precluded discrimination between monogenic and digenic genetic control. Where progeny phenotypic ratios of $1: 1$ resulted from a homozygote $\times$ diallelic heterozygote cross, no quantitative distinction could be made between diploid and tetraploid inheritance at that locus. Six putative enzyme loci were monomorphic among the four parents: $M d h-3, M d h-4$, Got-1, Got-2, Got-4, and Pgi-1.

\section{DISCUSSION}

Segregation ratios at four enzyme loci were in close agreement with a genetic model which included (1) tetrasomic inheritance, (2) codominant expression of alleles coding for dimeric enzymes, and (3) random chromosome segregation. In conjunction with the previous report of "albino seedling" inheritance (Draper and Scott, 1971), our report of tetrasomic segregation of allozyme markers provides strong evidence for an autopolyploid origin of $V$. corymbosum. The data were concordant with several other aspects of autotetraploidy. There was no evidence of fixed heterozygosity, which is a predictable and consistently observed consequence of allopolyploidy (Roose and Gootleib, 1976; Gottlieb, 1981; Werth et al., 1985). Differences in gene copy number (dosage) resulted in multiple diallelic phenotypes at a single locus. Electrophoretic surveys of several taxa have shown that, as expected, autotetraploid individuals can carry up to four different alleles per locus (Quiros, 1982; Crawford and Smith, 1984; Soltis and Rieseberg, 1986). Tri- and tetra-allelic genotypes were not present in this study. However, a survey of a natural $V$. corymbosum population in Michigan has revealed multiple allelism at the Pgi-2, Pgm-2, and Mdh-1 loci (Krebs and Hancock, unpublished).

No chromatid segregation was observed in our crosses. Double reduction events would have been detectable, for example, as aaaa progeny resulting from an $a b b b \times a b b b$ cross. For all segregating loci in the present study, there was at least one cross involving parental genotypes diagnostic for these exceptional events. The lack of double reduction segregants is somewhat surprising, since multivalent formation-a prerequisite for this kind of genetic non-disjunction-is reported in tetraploid highbush blueberries. One to five quadrivalents per cell were observed in clones which exhibited primarily bivalent associations (Rousi, 1966; Jelenkovic and Harrington, 1971). It is quite possible that the marker allozymes used in this analysis map to homologues which do not form multivalents. Lack of chromatid segregation in Heuchera grossulariifolia (Wolf et al., submitted) and $H$. micrantha (Soltis and Soltis, 1989) was attributed to localization of enzyme loci on short chromosomes $(\sim 2 \mu \mathrm{m})$ with low chiasma frequencies. Multivalent formation may be similarly restricted by the small size of many Vaccinium chromosomes, which vary from 1.3 to $2.5 \mu \mathrm{m}$, with 10 of the 12 chromosomes less than $2 \mu \mathrm{m}$ in length (Hall and Galletta, 1971). Regardless of whether or not they map to bivalent or multivalent-forming chromosomes, these marker allozymes may also be centromere-linked and thus restricted in crossing-over. 
Either scenario would result in random chromosome segregation based on the electrophoretic evidence.

Several lines of evidence indicate that there has been little genomic divergence during speciation in the Cyanococcus subgenus. Tetrasomic inheritance in $V$. corymbosum indicates that its diploid progenitors are probably geographic races of a common species. Structural and genetic homology of the Vaccinium genome is also evidenced by the lack of chromosome karyotype differences among diploid species (Hall and Galletta, 1971) as well as the high degree of interspecific fertility within the three predominant ploidal levels (Galletta, 1975; Ballington and Galletta, 1978). It has been noted (Lyrene and Ballington, 1986) that much of the current disagreement over species designations in this section (Camp, 1945; Vander Kloet, 1980) has its source in the confounding effects of frequent interspecific hybridization and differentiation of local races. Our report suggests that Camp's (1945) original assessment of both auto- and allopolyploids in Vaccinium section Cyanococcus was incorrect, and that the higher ploid taxa are probably polysomic polyploids like $V$. corymbosum.

Tetrasomic inheritance is a single-locus model for duplicate gene segregation. This feature, in contrast to the spontaneous generation of independent, duplicate loci by allotetraploidy, has notable genetic and evolutionary consequences. The adaptive success of polyploids (estimates as high as 50 per cent of all plant taxa) is frequently attributed to the ability of gene duplication events to increase levels of heterozygosity, create novel hybrid characters, and allow structural or functional divergence in gene expression (Roose and Gottlieb, 1976; Stebbins, 1980; Tal, 1980; Gottlieb, 1982; Levin, 1983; Soltis and Rieseberg, 1986). The extent to which these phenomena occur and are maintained in populations depends largely on the polyploid organism's origins and mode of inheritance.

Increased heterozygosity has been electrophoretically documented in allopolyploids (Roose and Gottlieb, 1976; Hart, 1983; Werth et al., 1985) and autopolyploids (Soltis and Rieseberg, 1986; Lumaret, 1986; Ness et al., 1989) relative to their diploid ancestors. Enzyme multiplicity in either type of polyploid may confer biochemical versatility and genotypic "buffering": in allopolyploids, increased heterozygosity frequently has the added advantage of resulting in novel heteromeric enzymes not found in the diverged diploid parent species (Roose and Gottlieb, 1976; Werth et al., 1985). Electrophoretic variation in autopolyploids is typically not unique, since it represents a subset of the diversity which already exists in the common ancestor taxon (Crawford and Smith, 1984; Soltis and Rieseberg, 1986; Ness et al., 1989).

Strategies for maintaining heterozygosity differ between the two types of polyploids. In response to inbreeding, tetrasomic polyploids have a much slower approach to homozygosity than disomic polyploids (Haldane, 1930), but where autotetraploids can ultimately be fixed (four identical alleles) at single loci, multilocus allotetraploids are buffered against homozygosis by fixed heterozygosity. Mating systems are present which complement these differences. All autopolyploids, including $V$. corymbosum (Krebs and Hancock, 1988), maintain heterozygosity via crossfertilization and exhibit low fertility in response to inbreeding. In contrast, most allopolyploids are self-compatible and several are predominantly self-pollinated (MacKey, 1970).

Tetrasomy versus disomy will also affect the likelihood of duplicate gene divergence. Redundant, independently segregating loci are required to allow fixation of null alleles or alleles with altered specificity. Hence the best examples of gene silencing or divergence among polyploids are disomic organisms such as Triticum aestivum (Hart, 1983), Chenopodium quinona (Wilson et al., 1983), or the catastomid fishes (Buth, 1983). According to Levin (1983), autopolyploids are expected to undergo duplicate gene evolution at a much slower rate than allopolyploids, since a shift from tetrasomic to disomic segregation is required. There is no clear evidence that this process has actually occurred in a polysomic polyploid. The presence of multiallelic genotypes and gene dosage effects in polyploid species of Medicago (Quiros, 1982), Solanum (Martinez-Zapater and Oliver, 1984), Tolmiea (Soltis and Soltis, 1988), Coreopsis (Crawford and Smith, 1984), and Vaccinium (present study), is evidence that duplicate genes have maintained expression. Duplicate gene silencing was reported in an autotetraploid lily species, Urginia maritima, a conclusion which was based on the appearance of individuals homozygous for nulls at an esterase locus (Oliver et al., 1983). However, other genotypes expressed alleles at this locus, suggesting that functional and non-functional allozymes were segregating at a single locus, and that gene silencing had not occurred at the population level. Salmonid fishes provide a single putative instance of an ancient autopolyploid which has passed from tetrasomy to disomy ("residual" tetrasomic inheritance occurs at some enzyme loci, in males only) and subsequently 
shows divergence of duplicate gene expression (Allendorf and Thorggaard, 1984; Buth, 1983).

Whether or not the subgenus Vaccinium section Cyanococcus meets the expectations of autopolyploid evolution remains to be established. Indeed, polysomic inheritance has yet to be determined in other tetraploid and hexaploid blueberry species. Furthermore, comparative studies of diploid, tetraploid, and hexaploid populations are required to determine the genetic consequences of genome amplification in this section. Studies of isoenzyme variation offer a valuable approach to these problems. A growing body of evidence, including the identification of "new" autopolyploids, indicates that polysomic speciation is fairly prevalent and not necessarily maladaptive (Levin, 1983; Soltis and Soltis, 1988).

Acknowledgements The authors would like to thank Dave Douches and Doug Soltis for their helpful comments on an earlier version of this paper. The efforts of LuAnn Gloden in preparing the manuscript are greatly appreciated.

\section{REFERENCES}

AllendorF, F. W. AND THORgGaARD, G. H. 1984. Tetraploidy and the evolution of Salmonid fishes. In Turner, B. J. (ed.) Evolutionary Genetics of Fishes, Plenum Press, New York, pp. 1-53.

ARULSEKAR, S., BRINGHURST, R. S. AND VOTH, V. 1981. Inheritance of PGI and LAP isozymes in octaploid cultivated strawberries. J. Amer. Soc. Hort. Sci., 106, 679-683.

BALLINGTON, J. R. AND GALLETTA, G. J. 1978. Comparative crossability of 4 diploid Vaccinium species. J. Amer. Soc. Hort. Sci., 103, 554-560.

BUTH, D. G. 1983. Duplicate isozyme loci in fishes: origins, distributions, phyletic consequences, and locus nomenclature. In Rattazzi, M. C., Scandalios, J. G., and Whitt, G. S. (eds) Isozymes, Vol. 10: Genetics and Evolution, A. R. Liss, New York, pp. 381-400.

CAMP, W. H. 1945. The North American blueberries with notes on other groups of Vacciniaceae. Brittonia, 5, 203-275.

CLAYTON, J. W. AND TRETIAK, D. N. 1972. Amine-citrate buffers for $p \mathrm{H}$ control in starch gel electrophoresis. $J$. Fisheries Res. Board. Can., 29, 1169-1172.

COCKERHAM, L. E. AND GAllettA, G. J. 1976. A survey of pollen characteristics in certain Vaccinium species. J. Amer. Soc. Hort. Sci., 101, 671-676.

CONKLE, M. T., HODGSKISS, P. D., HUNNALLY, L. B. AND HUNTER, S. C. 1982. Starch gel electrophoresis of conifer seeds: a laboratory manual. USDA Forest Service Technical Report PSW-64, Pacific Southwest Forest and Range Experiment Station, Berkeley.

CRAWFORD, D. J. AND SMITH, E. B. 1984. Allozyme divergence and intraspecific variation in Coreopsis grandiflora (Compositae). Syst. Bot., 9, 219-225.

DRAPER, A. D. AND SCOTT, D. H. 1971. Inheritance of albino seedlings in tetraploid highbush blueberry. J. Amer. Soc. Hort. Sci., 96, 791-792.
GAlletTA, G. J. 1975. Blueberries and cranberries. In Moore, J. N. and Janick, J. (eds) Advances in Fruit Breeding, Purdue Univ. Press, Lafayette, pp. 154-196.

GOTTLIEB, L. D. 1981. Electrophoretic evidence and plant populations. Progress Phytochem., 7, 1-47.

GOTTLIEB, L. D. 1982. Conservation and duplication of isozymes in plants. Science, 216, 373-380.

HALDANE, J. B. S. 1930. Theoretical genetics of autopolyploids. J. Genet., 22, 359-372.

HALl, S. H. AND GALleTtA, G. J. 1971. Comparative chromosome morphology of diploid Vaccinium species. J. Amer Soc. Hort. Sci., 96, 289-292.

HART, G. E. 1983. Genetics and evolution of multilocus isozymes in hexaploid wheat. In Rattazzi, M. C., Scandalios, J. G. and Whitt, G. S. (eds) Isozymes, Vol. 10: Genetics and Evolution, A. R. Liss, New York, pp. 365-380.

HAUBER, D. P. 1986. Autotetraploidy in Haplopappus spinulosus hybrids: evidence from natural and synthetic tetraploids. Amer. J. Bot., 73, 1595-1606.

JELENKOVIC, G. AND HARRINGTON, E. 1971. Nonrandom chromsome associations at diplotene and diakinesis in a tetraploid clone of Vaccinium australe Srnall, Can. J. Genet. Cytol., 13, 270-276.

JELENKOVIC, G. AND HOUGH, F. 1970. Chromosome associations in the first meiotic division in three tetraploid clones of Vaccinium corymbosum L. Can. J. Genet. Cytol., 12, 316-324.

KREBS, S. L. AND HANCOCK, J. F. 1988. The consequences of inbreeding on fertility in Vaccinium corymbosum. J. Amer. Soc. Hort. Sci., 113, 914-918.

LEVIN, D. A. 1983. Polyploidy and novelty in flowering plants. Am. Nat., 122, 1-25.

LUMARET, R. 1986. Doubled duplication of the structural gene for cytosolic phosphoglucose isomerase in the Dactylis glomerata L. polyploid complex. Mol. Biol. Evol., 3, 499. 521.

LYRENE, P. M. 1988. An allele for anthocyanin-deficient foliage, buds, and fruit in Vaccinium elliottii. J. Hered., 79, 8082.

LYRENE, P. M. AND BALLINGTON, J. R. 1986. Wide hybridization in Vaccinium. Hort. Sci., 21, 52-57.

MACKEY, J. 1970. Significance of mating systems for chromosomes and gametes in polyploids. Hereditas, 66, 165-176.

MARTINEZ-ZAPATER, J. M. AND OLIVER, J. L. 1984. Genetic analysis of isozyme loci in tetraploid potatoes (Solanum tuberosum L.). Genetics, 108, 669-679.

NEWCOMER, E. H. 1941. Chromosome markers of some species and varieties of Vaccinium and related genera. Proc. Amer Soc. Hort. Sci., 38, 468-470.

NESS, B. D., SOLTIS, D. E. AND SOLTIS, P. S. 1989 Autopolyploidy in Heuchera micrantha (Saxifragaceae). Amer. J. Bot., 76, 614-626.

OLIVER, J. L., MARTINEZ-ZAPATER, J. M., PASCUAL, L., ENRIQUEZ, A. M., RUIZ-REJON, C. AND RUIZ-REJON, M. 1983. Different genome amplication mechanisms and duplicate gene expression in Liliaceae. In Rattazzi, M. C., Scandalios, J. G. and Whitt, G. S. (eds) Isozymes, Vol. 10: Genetics and Evolution, A. R. Liss, New York, pp. 341363.

QUIROS, C. F. 1982. Tetrasomic inheritance for multiple alleles in alfalfa. Genetics, $101,117-127$.

QUiROS, C. F. AND McHALE, N. 1985. Genetic analysis of isozyme variants in diploid and tetraploid potatoes. Genetics, 111, 131-145.

RoOSE, M. L. AND GOTTLIEB, L. D. 1976. Genetic and biochemical consequences of polyploidy in Tragopogon. Evolution, 30, 818-830. 
Rousı, A. 1966. Cytological observations on some species and hybrids of Vaccinium. Zuchter/Gen. Brdg. Res., 36, 352359.

SCANDALIOS, J. G. 1969. Genetic control of multiple molecular forms of enzymes in plants: a review. Biochem. Genet., 3, 37-79.

SOLTIS, D. E., HAUFLER, C. H., DARROW, D. C. AND GASTONY, G. J. 1983. Starch gel electrophoresis of ferns: A compilation of grinding buffers, gel and electrode buffers, and staining schedules. Amer. Fern. J., 73, 9-27.

SOLTIS, D. E. AND RIESEBERG, L. H. 1986. Autopolyploidy in Tolmiea menziesii (Saxifragaceae). Amer. J. Bot., 73, 310318.

SOLTIS, D. E. AND SOLTIS, P. S. 1988. Electrophoretic evidence for tetrasomic segregation in Tolmiea menziesii (Saxifragaceae). Heredity, 60, 375-382.

SOLTIS, D. E. AND SOLTIS, P. S. 1989 Tetrasomic inheritance in Heuchera micrantha (Saxifragaceae). J. Hered., 80, 123126.

STEBBINS, G. L. 1980. Polyploidy in plants: Unsolved problems and prospects. In Lewis, W. H. (ed.) Polyploidy, Plenum Press, New York, pp. 495-520.

STUSHNOFF, C. AND HOUGH, L. F. 1968. Sporogenesis and gametophyte development in "Bluecrop" and "Colville" highbush blueberries. Proc. Amer. Soc. Hort. Sci., 93, 242247.
TAL, M. 1980. Physiology of polyploids. In Lewis, W. H. (ed.). Polyploidy, Plenum Press, New York, pp. 61-75.

VALLEJOS, C. E. 1984. Enzyme activity staining. In Tanksley, S. D. and Orton, T. J. (eds). Isozymes in Plant Genetics and Breeding, Part A, Elsevier Science, Amsterdam, pp. 469516.

VANDER KLOET, S. P. 1980. The taxonomy of the highbush blueberry, Vaccinium corymbosum. Can. J. Bot., 58, $1187-$ 1201.

WERTH, C. H., GUTTMAN, S. F. AND ESHBAUGH, W. H. 1985. Electrophoretic evidence of reticulate evolution in the Appalachian Asplenium complex. Systm. Bot., 10, 184-192.

WILSON, H. D., BARBER, S. C. AND WALTERS, T. 1983. LosS of duplicate gene expression in tetraploid Chenopodium. Biochem. Syst. Ecol., 11, 7-13.

WOLF, P. G., SOLTIS, P. S. AND SOLTIS, D. E. Tetrasomic inheritance and chromosome pairing behavior in the naturally occurring autotetraploid Heuchera grossulariifolia (Saxifragaceae). Genome. (Submitted). 